\section{What is already known on this topic}

The reference treatment for erysipelas is intravenous penicillin, which requires admission to hospital

Few studies have evaluated the efficacy of oral treatment for erysipelas

\section{What this study adds}

Oral pristinamycin is at least as effective as intravenous then oral penicillin to treat erysipelas in adult inpatients, with the advantage of oral first line treatment

non-inferiority of pristinamycin versus penicillin, the primary end point relies on the per protocol analysis. ${ }^{13}$ Full application of the intention to treat analysis will be possible only once complete outcome data become available for all randomised patients. ${ }^{17}$ Most of our non-assessable patients were excluded from the per protocol analysis because of adverse events leading to premature withdrawal, missing data, or use of prohibited treatment. Intention to treat analysis also confirmed the non-inferiority of pristinamycin as inclusion of non-compliers decreased the cure rates to similar extents in both groups.

Currently, pristinamycin is marketed only in some European countries. It is commonly used in France to treat erysipelas ${ }^{18}$ and superficial pyodermas ${ }^{19}$ in outpatients. Our results show that pristinamycin could be an alternative to intravenous then oral penicillin to treat erysipelas in adult inpatients. Whether this therapeutic strategy is valid for outpatients needs to be investigated.

We are grateful to $\mathrm{C}$ Jean, Y Boutalbi, and $\mathrm{O}$ Lescale (Laboratoire Aventis) for their help in the data analysis and preparation of the manuscript and P Joffre-Malamas (Laboratoire Aventis) for the statistical analysis. See bmj.com for a list of members of the French Erysipelas Study Group.

Contributors: See bmj.com
Funding: Aventis (Paris, France).

Competing interests: $\mathrm{PB}, \mathrm{OC}$, and $\mathrm{LV}$ have received fees from Aventis for helping to design and organise the study and review difficult cases (steering committee)

1 Bernard P, Bedane C, Mounier M, Denis F, Catanzano G, Bonnetblanc JM. Streptococcal cause of erysipelas and cellulitis in adults: a microbiologic study. Arch Dermatol 1989;125:779-82

2 Duvanel T, Auckenthaler R, Rohner P, Harms M, Saurat JH. Quantitative cultures of biopsy specimens from cutaneous cellulitis. Arch Intern Med 1989;149:293-6.

3 Chartier C, Grosshans E. Erysipelas. Int J Dermatol 1990;29:459-67

4 Swartz MN. Cellulitis and subcutaneous tissue infections. In: Mandell GL, Bennett JE, Dolin R, eds.Principles and practice of infectious diseases. New York: Churchill Livingstone 1995:909-15.

5 Bisno AL, Stevens DL. Streptococcal infections of the skin and soft tissues. N Engl J Med 1996;334:240-5.

6 Dupuy A, Benchikhi H, Roujeau JC, Bernard P, Vaillant L, Chosidow O, et al. Risk factors for erysipelas of the leg (cellulitis): case-control study. BMJ 1999;318:1591-4.

7 Jorup-Rönström C. Epidemiological, bacteriological and complicating features of erysipelas. Scand J Infect Dis 1986;18:519-24.

8 Chartier C, Grosshans E. Erysipelas: an update. Int I Dermatol 1996;35:779-81.

9 Ronnen P, Suster S, Schewach-Millet M, Modan M. Erysipelas: changing faces. Int J Dermatol 1985;24:169-72.

10 Jorup-Rönström C, Britton S, Gavlevick A, Gunnarson AC. The course, costs and complications of oral versus intravenous penicillin therapy of erysipelas. Infection 1984;12:390-4.

11 Schmit JL. Enquête prospective. Erysipèle et cellulites nécrosantes: quelle prise en charge en milieu hospitalier? Ann Dermatol Vénéréol 2001;128:334-7.

12 Bernard P, Plantin P, Roger H, Sassolas B, Villaret E, Legrain V, et al. Roxithromycin versus penicillin in the treatment of erysipelas in adults: a comparative study. Br J Dermatol 1992;127:155-9.

13 Committee for Proprietary Medicinal Products, European Agency for the Evaluation of Medicinal Products. Points to consider on switching between superiority and non-inferiority. London: EAEMP, 2000 (CPMP/EWP/482/99)

14 Bergkvist PI, Sjöbeck K. Antibiotic and prednisolone therapy of erysipelas: a randomised, double-blind, placebo-controlled study. Scand J Infect Dis 1997;29:377-8.

15 Erysipèle et fasciite nécrosante: prise en charge. Conférence de consensus. Ann Dermatol Vénéréol 2000;127:1118-37.

16 Siegel JP. Equivalence and noninferiority trials. Am Heart $J$ 2000;139(suppl):S167-70

17 Jones B, Jarvis P, Lewis JA, Ebbutt AF. Trials to assess equivalence in medical research: are they supported by the evidence? BMJ 1996;313:36-9.

18 Kopp M, Schmit JL, Bernard P. Prise en charge des dermohypodermites bactériennes par les médecins généralistes: enquête de pratique et étude prospective. Ann Dermatol Vénéréol 2001;128:338-44.

19 Bernard P, Vaillant L, Martin C, Beylot C, Quentin R, Touron D. Pristinamycine (Pyostacine 500) versus oxacilline dans le traitement des pyodermites superficielles: résultats d'une étude randomisée multicentrique chez 293 malades ambulatoires. Ann Dermatol Vénéréol 1997; 124:384-9.

(Accepted 6June 2002)

\title{
Effect of general hospital management on repeat episodes of deliberate self poisoning: cohort study
}

Navneet Kapur, Allan House, Kath Dodgson, Chris May, Francis Creed

Department of Psychiatry and Behavioural Sciences,

Manchester Royal Infirmary,

Manchester

M13 9WL

Navneet Kapur

lecturer

Kath Dodgson

research assistant

Chris May

research assistant

Francis Creed

professor

continued over

BMJ 2002;325:866-7
Provision of services in the United Kingdom for patients who deliberately poison themselves is variable, and many patients leave hospital without adequate assessments. ${ }^{1}$ This may reflect the equivocal research evidence on the effectiveness of interventions. ${ }^{2}$ In this cohort study, we aimed to investigate whether aspects of routine hospital management-such as admission, psychosocial assessment, and referral for follow up-had an impact on the repetition of deliberate self poisoning.

\section{Participants, methods, and results}

Over eight weeks, we prospectively identified patients aged over 16 years who attended six general hospitals (three teaching; three district) in north west England for deliberate self poisoning. We examined the notes in accident and emergency departments for all patients (regardless of presenting complaint) to ensure that we did not miss any episodes. We also looked at databases held in wards and emergency departments and copies of specialists' self poisoning assessments, and we retrospectively checked the patient administration system in each hospital. We collected information about patients' characteristics, clinical details, and the management of the current episode, including whether the patient had received a psychosocial assessment (as defined by the Royal College of Psychiatrists). ${ }^{3}$ We followed participants for 12 weeks after their index episode, because half of those who poison themselves again do so within 
this period. ${ }^{4}$ Follow up data were taken from case notes and databases by a researcher blind to the patient's initial management.

In total, 604 people deliberately poisoned themselves during the recruitment period; $88(15 \%)$ of these poisoned themselves again within 12 weeks. Overall, 24/246 (10\%) patients who had received a psychosocial assessment and 64/358 (18\%) who had not received an assessment poisoned themselves again (table). Patients with certain risk factors for repetitionsuch as previous self poisoning, psychiatric history, and substance dependence-were more likely to receive a psychosocial assessment. We adjusted for these and other risk factors for repetition-such as sex, age, potential lethality of the episode, and self discharge from hospital-with a binary logistic regression model. ${ }^{5}$ We included psychosocial assessment in the model to investigate whether such assessment independently contributed to risk of repetition. After adjustment, patients who had not been assessed were still more likely to poison themselves again (adjusted odds ratio 2.3 (95\% confidence interval 1.4 to 3.9$), \mathrm{P}<0.005$ ).

\section{Comment}

Patients who had received a psychosocial assessment after deliberately poisoning themselves were half as likely to poison themselves again as those who did not, even though the patients who were assessed might be regarded as being at higher risk. The association held when we adjusted for risk factors for repetition, although we did not adjust for all possible confounders. The better outcome in those who were assessed compared with those who were not assessed may have reflected the type of aftercare, but this study provides no evidence that referral to a specialist reduced repetition. Our results suggest that 12 patients need to receive a psychosocial assessment to prevent one patient poisoning himself or herself again. If we assume that $50 \%$ of patients are assessed currently, we might prevent 7000 repeat episodes of self poisoning by complying with existing guidelines and ensuring that all patients are properly assessed. ${ }^{3}$

Our results should be interpreted cautiously because they are restricted to one region of the United Kingdom and include a comparatively short follow up period. The hospitals were representative of the services generally available for self poisoning, ${ }^{1}$ however, and most patients who poison themselves repeat the act soon after the
Risk of repetition of self poisoning in 604 patients presenting to six general hospitals in north west England

\begin{tabular}{lccc} 
Variable & $\begin{array}{c}\text { No of } \\
\text { patients }\end{array}$ & $\begin{array}{c}\text { No (\%) who } \\
\text { repeated self } \\
\text { poisoning }\end{array}$ & $\begin{array}{c}\text { Odds ratio } \\
\text { (95\% CI) for risk } \\
\text { of repetition }\end{array}$ \\
\hline Patients' characteristics & 330 & $52(16)$ & 0.8 (0.5 to 1.3) \\
\hline Female & 213 & $41(19)$ & $1.7(1.1$ to 2.8) \\
\hline Previous episode of self poisoning & 111 & $13(12)$ & $0.7(0.4$ to 1.4$)$ \\
\hline Dependent on drugs or alcohol & 145 & $18(12)$ & 0.8 (0.5 to 1.4) \\
\hline Index episode of high potential lethality & 112 & $19(17)$ & $1.3(0.7$ to 2.2) \\
\hline Psychiatric contact at time of index episode & & & \\
\hline Management of index episode & 91 & $13(14)$ & $1.0(0.5$ to 1.8$)$ \\
\hline Self discharged before assessment made & 358 & $64(18)$ & $2.1(1.2$ to 3.3) \\
\hline Did not receive psychosocial assessment & 208 & $30(14)$ & $1.0(0.6$ to 1.6$)$ \\
\hline Admitted to medical ward & 14 & $3(21)$ & $1.6(0.4$ to 6.0$)$ \\
\hline Admitted to psychiatric ward & 117 & $18(15)$ & 1.1 (0.6 to 2.0) \\
\hline Offered psychiatric follow up & & &
\end{tabular}

index episode. ${ }^{4}$ We did not identify repeat episodes in patients who did not present to hospital, and this is a potential source of bias.

Psychosocial assessments have a number of elements. ${ }^{5}$ Further research should identify and refine the components of psychosocial assessments that reduce the risk of repetition of self poisoning.

We thank Kevin Mackway Jones, Paul Strickland, Mike Brownlee, Bill Williams, Robin Ellis, and Jayne Cooper (director of Manchester and Salford Self Harm Project) for help with data collection and staff from the information departments at all centres for providing admission data. We also thank Iain W McGowan for his comments on the paper.

Contributors: NK and AH devised the study and wrote the initial draft of the paper. FHC advised on aspects of study design. $\mathrm{KD}$ and CM collected data and helped with aspects of study design. All authors contributed to the analysis and presentation of data and commented on drafts of the paper. NK is the guarantor for this study.

Funding: CM and KD were supported in part by an educational grant from SB Pharmaceuticals during the course of this study. Competing interests: None declared.

1 Kapur N, House A, Creed F, Feldman E, Friedman T, Guthrie E. Management of deliberate self poisoning in adults in four teaching hospitals: descriptive study. BMJ 1998;316:831-2.

2 Hawton K, Townsend E, Arensman E, Gunnell D, Hazell P, House A, et al. Psychosocial and pharmacological treatments for deliberate self harm. Cochrane Database Syst Rev 2001;(4):CD001764.

3 Royal College of Psychiatrists. The general hospital management of adult deliberate self-harm: a consensus statement on standards for service provision. London: Royal College of Psychiatrists, 1994.

4 Gilbody S, House A, Owens D. The early repetition of deliberate self harm. J R Coll Physicians Lond 1997;31:171-21.

5 Deliberate self-harm. Effective Health Care Bulletin 1998;4(6):1-12. http:// www.york.ac.uk/inst/crd/ehc46.pdf (accessed 30 May 2002).

(Accepted 13 March 2002)
Academic Unit of Psychiatry and Behavioural Sciences, University of Leeds, Leeds LS2 9JT

Allan House professor

Correspondence to: Williamson

Building, University of Manchester,

Manchester M13 9PL nav.kapur@ man.ac.uk $\mathrm{N}$ Kapur, 7th Floor

\section{A busy year of reading for medical students?}

A liberal education may be had at a very slight cost of time and money. Well filled though the day be with appointed tasks, to make the best possible use of your one or of your ten talents, rest not satisfied with this professional training, but try to get the education, if not of a scholar, at least of a gentleman. Before going to sleep read for half an hour, and in the morning have a book open on your dressing table. You will be surprised to find how much can be accomplished in the course of a year. I have put down a list of ten books which you may make close friends. There are many others; studied carefully in your student days these will help in the inner education of which I speak.
I. Old and New Testament.

II. Shakespeare.

III. Montaigne.

IV. Plutarch's Lives.

V. Marcus Aurelius.

VI. Epictetus.

VII. Religio Medici.

VIII. Don Quixote.

IX. Emerson

X. Oliver Wendell Holmes-Breakfast-Table Series.

Sir William Osler Aequanimitas 1906 